\title{
Modelling river and riparian vegetation interactions and related importance for sustainable ecosystem management
}

\section{Journal Article}

Author(s):

Perona, Paolo; Camporeale, Carlo; Perucca, Eliana; Savina, Maurizio; Molnar, Peter (D); Burlando, Paolo; Ridolfi, Luca

Publication date:

2009-10

Permanent link:

https://doi.org/10.3929/ethz-b-000021111

Rights / license:

$\underline{\text { In Copyright - Non-Commercial Use Permitted }}$

Originally published in:

Aquatic Sciences 71(3), https://doi.org/10.1007/s00027-009-9215-1 


\title{
Research Article
}

\section{Modelling river and riparian vegetation interactions and related importance for sustainable ecosystem management}

\author{
Paolo Perona $^{1}$, Carlo Camporeale ${ }^{2}$, Eliana Perucca ${ }^{2}$, Maurizio Savina ${ }^{1}$, Peter Molnar ${ }^{1}$, Paolo Burlando ${ }^{1}$ and \\ Luca Ridolfi ${ }^{2}$ \\ ${ }^{1}$ Institute of Environmental Engineering, ETH Zurich, 8093 Zurich, Switzerland \\ ${ }^{2}$ Politecnico di Torino and IDRAM, 10129 Turin, Italy
}

Received: 28 December 2008; revised manuscript accepted: 1 July 2009

\begin{abstract}
We discuss the importance of modelling riparian vegetation and river flow interactions under differing hydrologic regimes. Modelling tools have notable implications with regard to the understanding of riverine ecosystem functioning and to promote sustainable management of water resources. We present both deterministic and stochastic approaches with different levels of simplification, and discuss their use in relation to river and vegetation dynamics at the related scale of interest. We apply such models to both
\end{abstract}

meandering and braided rivers, in particular focusing on the floodplain dynamics of an alpine braided river affected by water impoundment. For this specific case we show what the expected changes in riparian vegetation may be in a 'controlled release' scenario for the postdam river Maggia, Switzerland. Finally, the use of these models is discussed in the context of current research efforts devoted to river restoration practice.

Key words. Ecohydrological models; floodplain dynamics; flow regulation; river morphodynamics; riparian vegetation; stochastic processes.

\section{Introduction}

Floodplain processes are the result of a number of variables (e.g., river hydraulics and transport processes, soil-water and nutrients, riparian plant communities, microorganisms and soil cohesion) interacting at different spatial and temporal scales (e.g., see Anderson et al., 1996), and of climatic forcing. Consider for instance riparian vegetation and the number of feedbacks arising from interactions with flow. Typically, vegetation occurs in patches (i.e., areas that differ from their surroundings in structure or function) along river corridors, with species selected by a set of variables, of which topography is the most basic determinant, as an indirect effect of inundation (Poole et al., 2002). Riparian vegetation influences chemical and hydrogeomorphological conditions via transpiration, root-microbe-soil interactions and mechanical stabilization of river boundaries (Millar, 2000; Pollen and Simon, 2005). In turn, river bed and banks are influenced by the hydrologic regime (e.g., timing, frequency, magnitude and duration of flooding events), the moisture in the soil substrate and the time since patches were established. A combination of all these factors determine how resistant vegetation is against flood disturbances. As well, the life cycle of vegetation also influences river morphodynamics by promoting the formation and the stabilization of early island nuclei, and in turn influences the functioning of the entire ecosystem (Gurnell et al., 2001; Gurnell and Petts, 2006). 
In this work, we address the use of mathematical models to study coupled river and vegetation dynamics. A complete picture of the interrelations involved among all the variables playing a role in such processes is currently not possible. However, microscopic scale processes can be usefully parameterized into bulk descriptive quantities, thus reducing the number of active variables when modelling the macroscale. For instance, river hydrology, sediment erosion and deposition, and riparian vegetation evolution establish both positive and negative feedbacks that explain many geomorphic features observed in natural river patterns (Rodriguez-Iturbe and Rinaldo, 1997; Perucca et al., 2007). It is now clear that such feedbacks emerge as long as vegetation cover is not only considered as a passive mechanical element (e.g., merely increasing the local river or bank roughness), but a living organism with its characteristic biological time scales. When such biological time scales start interacting with the hydrologic ones, then new geomorphic patterns begin to appear as has been shown recently both experimentally (Gran and Paola, 2001; Coulthard, 2005; Tal and Paola, 2007) and by models (Glenz, 2005; Camporeale and Ridolfi, 2006; Perucca et al., 2006; Camporeale and Ridolfi, 2007; Perucca et al., 2007; Perona et al., 2008; Muneepeerakul et al., 2007).

Both detailed deterministic and minimalist stochastic models have recently been developed depending on the type of riverine environment being investigated. Deterministic models are usually physically based and use the equations of river morphodynamics (Seminara, 1998; Camporeale et al., 2007) coupled to some empirical model equations of vegetation development. Such models are particularly well developed for meandering rivers (Tubino and Seminara, 1990; Mosselman, 1998; Imran et al., 1999; Zolezzi and Seminara, 2001; Camporeale et al., 2007), the dynamics of which has been widely investigated via both extensive numerical simulations, and analytical techniques. Promising results have however recently been obtained with regard to the branching dynamics that characterize braided rivers (Murray and Paola, 2003; Bolla Pittaluga et al., 2003; Coulthard et al., 2007; Jang and Shimizu, 2007; Bertoldi et al., 2006; Bertoldi and Tubino, 2007). Minimalist stochastic modelling approaches are particularly suitable to study those processes whose dynamics may be strongly blurred by environmental noise, but the skeleton of which may be captured if adequate simplifications are made. By keeping the model mathematically tractable one can often find analytical solutions that are able to elucidate the quantitative links among the main variables that regulate the dynamics. This modelling approach makes use of the theory of stochastic processes (Van
Kampen, 1992) and has been successful in several branches of biogeosciences, e.g. to model vegetation pattern formation (Lefever and Lejeune, 1997; Klausmeier, 1999; D'Odorico et al., 2006; Rietkerk and Van de Koppel, 2008), ecohydrological and snow processes (Rodriguez-Iturbe et al., 1999; D’Odorico et al., 2005; Rodrigez-Iturbe and Porporato, 2005; Laio et al., 2006; Perona et al., 2007), plant physiology features (Hutt and Luttge, 2002), and more recently to describe some aspects of riparian vegetation ecosystems (Camporeale and Ridolfi, 2006, 2007; Muneepeerakul et al., 2007; Perona et al., 2008).

In this paper we demonstrate the applicability of different modelling approaches to interpret the river and riparian vegetation dynamics within the chosen systems, that are both meandering and braided rivers (see the scheme in Fig. 1). Whilst the use of deterministic models for meandering rivers is mainly a discussion of previously obtained results (next section), the novelty in this paper concerns the application of minimalist models to water-impounded $\mathrm{Al}$ pine braided systems. In particular, we choose the Maggia River (Maggia valley, Canton Tessin, $\mathrm{CH}$ ) as reference river, and apply the stochastic models of Camporeale and Ridolfi (2006) and Perona et al. (2008). We first show how the floodplain dynamics have changed during the postdam period, and then make a quantitative analysis of the riverine corridor evolution under changing hydrologic scenarios. That is, we offer a discussion about the effects that artificial disturbances may have on the floodplain dynamics. This aspect has obvious implications as far as the future management of the water resources in the valley is concerned.

\section{Deterministic modelling approach}

\section{Application to meandering rivers}

Meandering rivers are very common in nature and, due to their planimetric migration in the floodplain, they interact closely with their riparian ecosystem and with human structures (Perona and Camporeale, 2004). Their study is therefore important from both an engineering and an environmental viewpoint. In this fluvial context, biomorphodynamic models have only recently been proposed (Brookes et al., 2000; Baptist et al., 2004; Van De Wiel and Darby, 2004; Baptist et al., 2005; Hooke et al., 2005; Larsen et al., 2006; Perucca et al., 2006, 2007). However, most of these models that refer to meandering rivers do not consider the active role of vegetation (Van De Wiel and Darby, 2004; Baptist et al., 2004; Larsen et al., 2006; Perucca et al., 2006). Differently, Perucca et al. (2007) introduced the coupling between meandering 


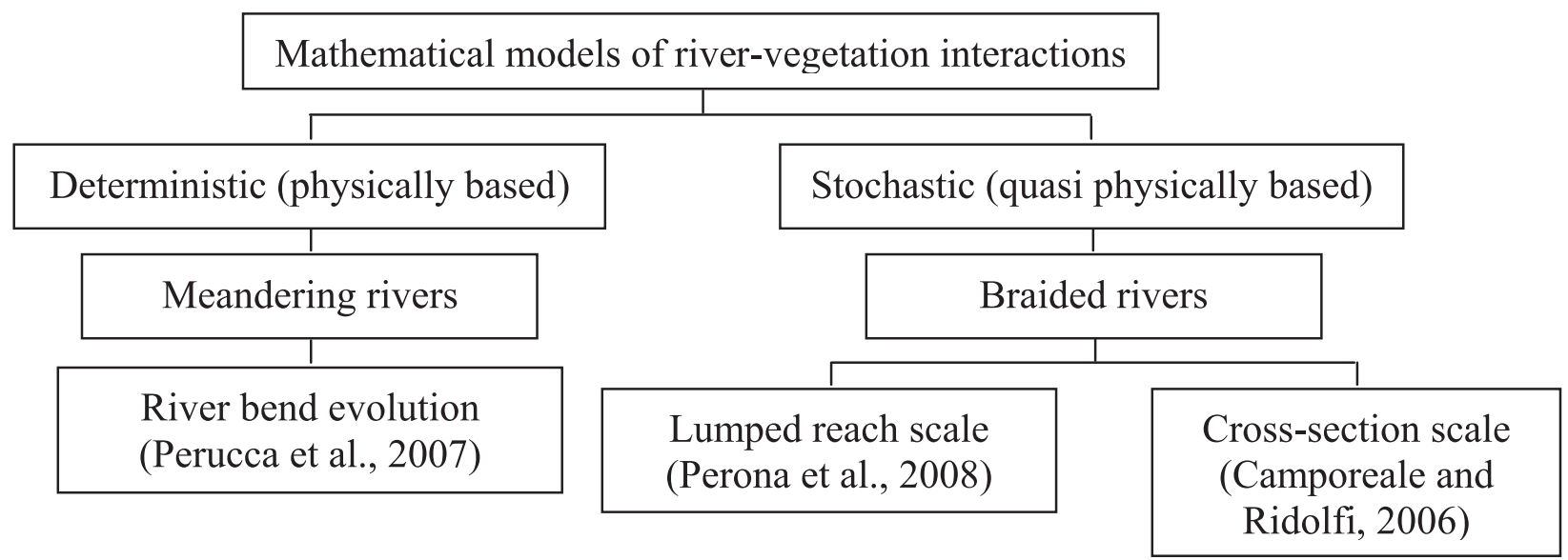

Figure 1. Scheme of river-vegetation mathematical models that are discussed and applied to different fluvial environments in this work.

river and riparian vegetation dynamics. Since the coupled dynamics of the river and the vegetation are complex, it is useful to investigate separately the active from the passive role of vegetation. This is the reason why Perucca et al. (2006) proposed, at first, a model where only the river induced vegetation patterns are focused, and subsequently, a more advanced model (Perucca et al., 2007).

More in detail, Perucca et al. (2006, 2007) summarized the effects of the main river-induced processes on riparian vegetation, using three typical steady state distributions of biomass densities along a river transect. The steady distributions establish when the river does not migrate across the floodplain. Such distributions are the result of the dominant hydrological mechanisms that affect the riparian vegetation in the river system that is taken into consideration (Fonda, 1974; Nanson and Beach, 1977; Bradley and Smith, 1986). A first typical shape of stationary density distribution (called F1, see Fig. 2) emerges when water table depth is the main control of the river on the riparian vegetation ecosystem. The biomass density has a maximum at the river bank and then decreases. In these cases, riparian vegetation can draw water and nutrients mainly in the proximity of a river, while, moving away from the river bank, vegetation thins out. This is the case of semi-arid region (Carr, 1998), but also of mild and humid ones (Brookes and Brierley, 2002). On the other hand, if the action of a flood is the main geomorphological element acting on the vegetation development, density functions, which give lower values close to the river bank and increase moving away from the river, can be suggested (called F2). In this case, the vegetation close to the river is destroyed by extirpation or dies from burial under the transported sediments and from anoxia because of prolonged persistence of high water levels (Bradley and Smith, 1986). Finally, when the concurrent action of the water table, sedimentation and flooding is considered, the riparian vegetation density reaches a maximum at a certain distance from the river (density function called F3). This distance depends on the relative significance of concurrent action of the above said physical elements. A density function shaped in this way was documented by Nanson and Beach (1977) for the Beatton River (British Columbia, Canada).

Let us consider now that the river migrates: the distance of the vegetation sites from the river changes and riparian vegetation tends to accommodate the stationary density value that corresponds to the actual distance from the river bank. This temporal evolution of biomass density is described by a curve of a logistic type if the biomass increases, or by an exponential decay, if the biomass density decreases. As a result, the planimetric evolution of a river and its riparian vegetation dynamics are coupled and the riparian vegetation continuously changes in space and time as forced by river migration.

Figure 3 shows a result obtained from the numerical simulation of the model of Perucca et al. (2006) with the function F3. These results highlight the emergence of vegetation patterns due to river movement in the case where the temporal scale of vegetation evolution and the temporal scale of the river are comparable (Perucca et al., 2006). In order to model the active role of vegetation, Perucca et al. (2007) introduced vegetation-dependent bank erodibility. This implies a bi-directional coupling between vegetation and river dynamics. A river in fact comes into contact with sites with different vegetation densities during migration in the floodplain; this affects bank erodibility and also influences river migration itself. For example, consider the following dependence of the erodibility $E$ on the dimensionless biomass $v$ 


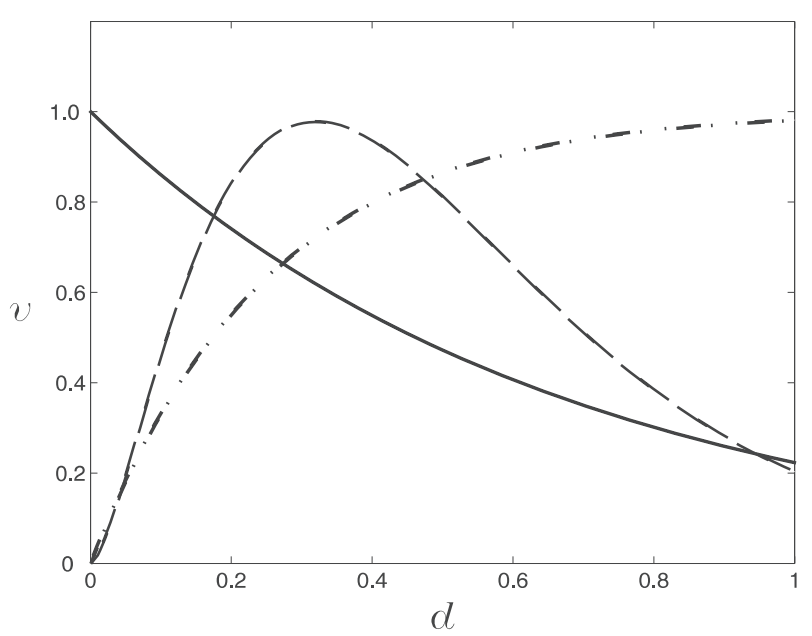

Figure 2. Example of stationary density distributions for riparian vegetation F1 (solid line), F2 (dash-dot line) and F3 (dashed line), according to the role played by floods and local environmental conditions. $d$ and $v$ are dimensionless distance and biomass, respectively.
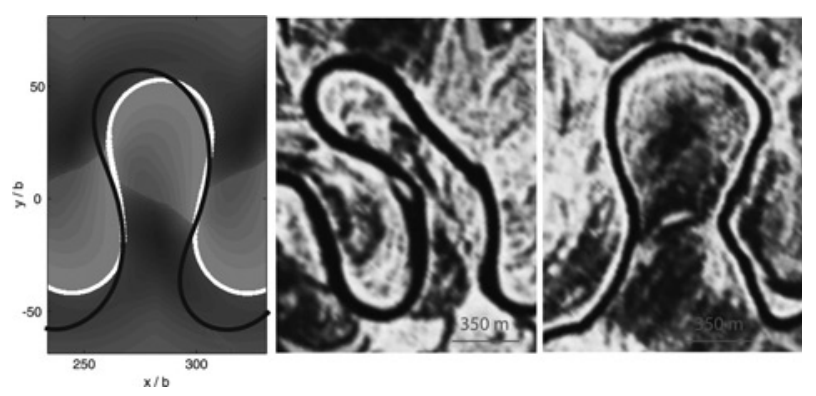

Figure 3. (Left panel) Comparison between river planforms obtained with function F3 by adopting vegetation-dependent erodibility (white line) and constant erodibility (black line). The variables are made non-dimensional with the river width $b$. Exemplary changing loop geometry for the same real meandering river near Egil Island, Alaska, county of Yukon-Koyukuk (CA) conditioned by low (middle panel, $66^{\circ} 15^{\prime} 33.00^{\prime \prime} \mathrm{N} ;-145^{\circ} 24^{\prime} 58.00^{\prime \prime}$, flow is from left to right) and high biomass density (right panel, $66^{\circ} 17^{\prime} 46.00^{\prime \prime}$; $-145^{\circ} 32^{\prime} 12.00^{\prime \prime}$, flow is from right to left).

$E=\left(E_{0}-E_{1}\right) \cdot\left(1-v_{*}^{\frac{(1-l)}{m}+1}\right)+E_{1}$,

where $v_{*}=\frac{v-v_{0}}{v_{1}-v_{0}}, E_{0}$ and $E_{1}$ are the erodibilities corresponding to the biomass amount $v_{0}$ and $v_{1}$, respectively, and $l$ and $m$ are two parameters that depend on the vegetation type and that can be estimated experimentally. When $l=1$, equation (1) becomes a linear law. Differently, an upward (for $l<0$ ) or a downward (for $l>0$ ) concavity of the curve $E=$ $E\left(v_{*}\right)$ is obtained. The proposed relationship between the vegetation density and erodibility has been chosen since it is able to model in a simple way various erodibility dependences. Figures 3 and 4 show the result of a vegetation dependent bank erodibility. First
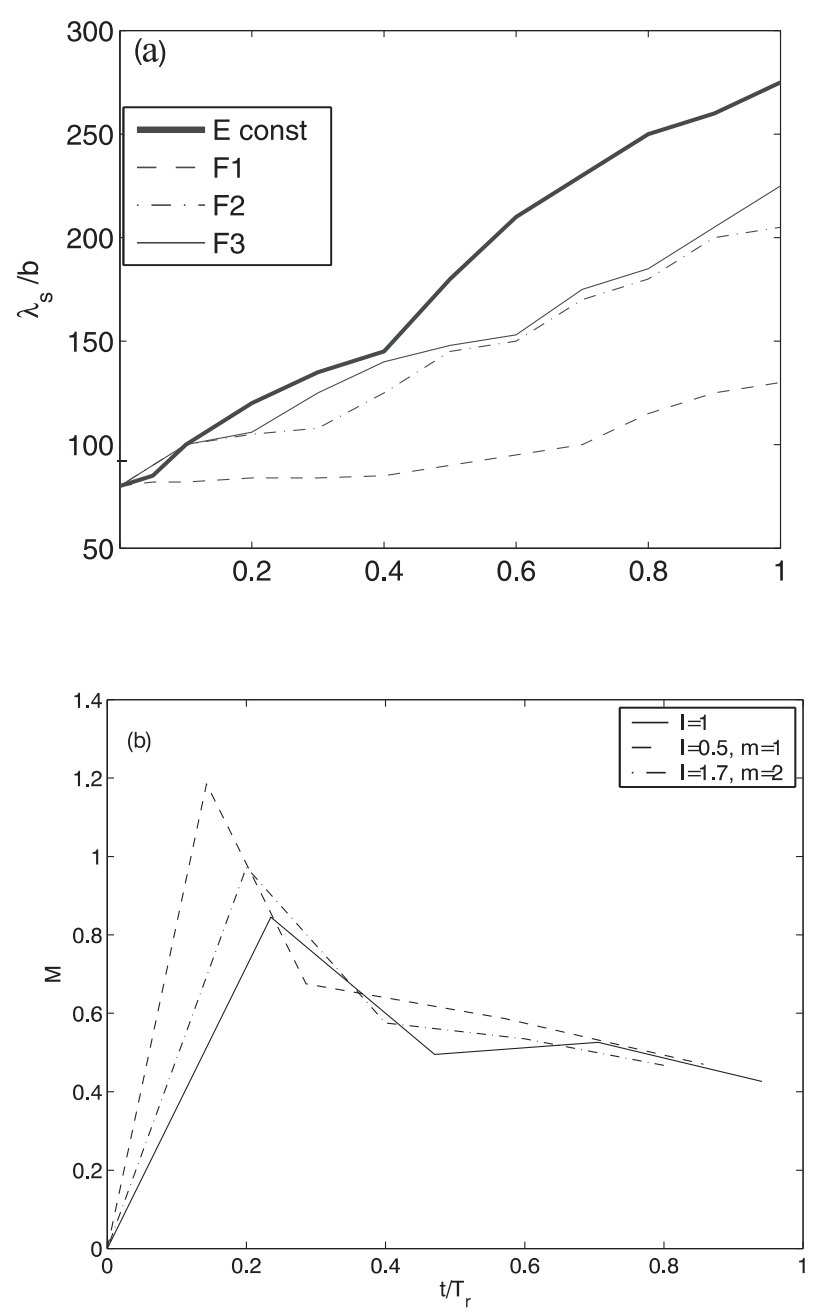

Figure 4. (a) Temporal evolution of the curvilinear wavelength, $X$, adopting the constant erodibility, and the three distributions $\mathrm{F} 1$, F2, and F3. (b) Temporal evolution of the migration rate $M$ adopting the three different dependencies of the erodibility from the Vegetation biomass. The time $t$ is made non-dimensional with the river temporal scale $T_{r}$ which is the time that the river spends to move a length equal to its mean half wavelength starting from a Kinoshita-shaped initial condition.

of all, figure 3 shows the differences in the simulated planimetric evolution of a meander bend when using vegetation biomass dependent (linear) erodibility with respect to a constant erodibility. Second, in figure 4a the curvilinear meander wavelengths are reported for the different stationary distributions of vegetation, and parameters $l=1.5$ and $m=2$, compared to the ones obtained with constant erodibility. Whatever transversal vegetation distribution is adopted, the simulation suggests that i) a vegetation-dependent erodibility entails a reduction in the meander length with respect to a constant erodibility, and ii) such differences are not negligible and influence mainly the entrance section of meander loops. For example, such differences can be of the order of hundreds of meters 

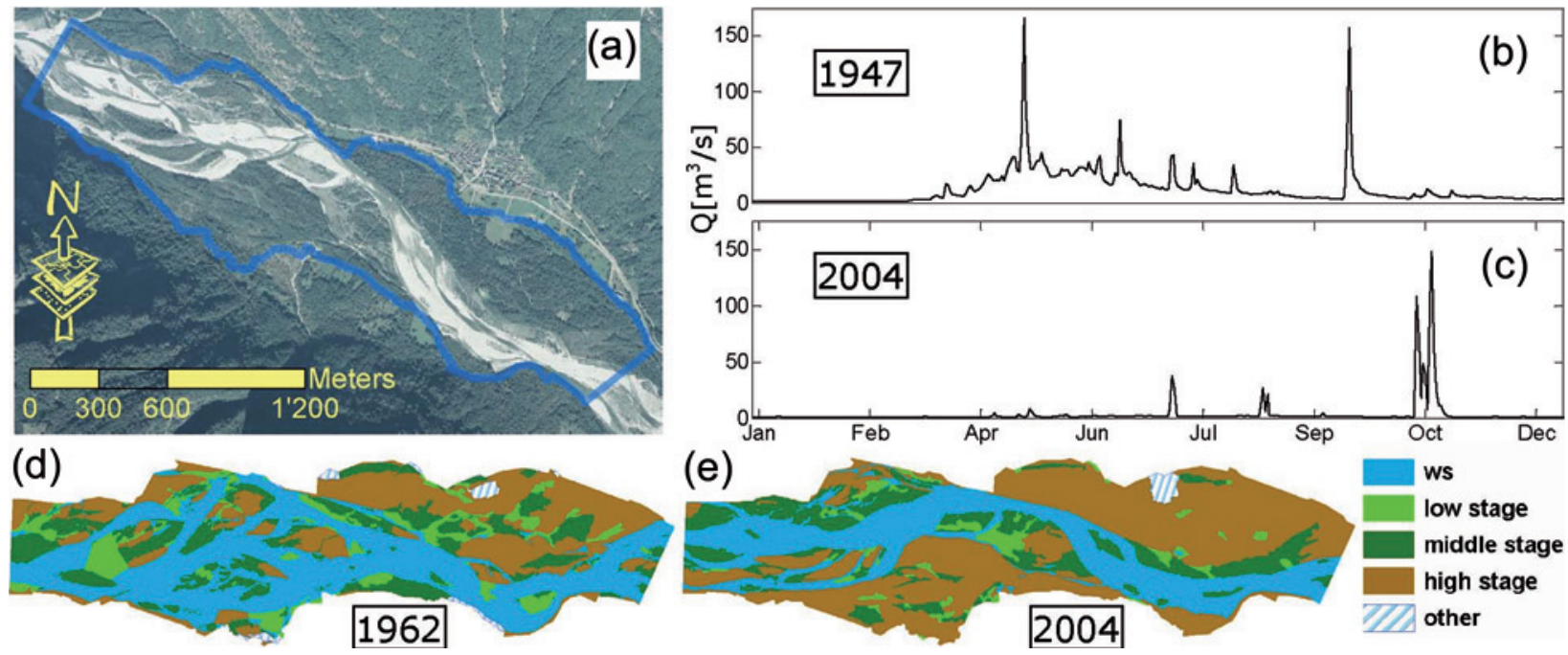

(d)

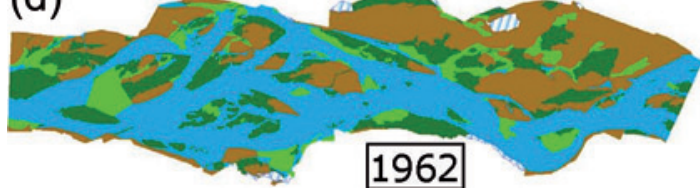

Figure 5. (a) Aerial photograph of the Maggia floodplain around Someo and domain of the lumped model (blue line). Typical predam annual hydrograph (b) and typical postdam one (c) showing the disappearance of the seasonal flow component. Map of the classes identified from the georeferenced photographs soon after the impoundment began (d) and more recently (e).

in real rivers. It should be noticed that the wavelength does not reach a final stationary value since the simulation was stopped before the occurrence of a neck cutoff. Figure 4(b) shows the temporal evolution of the migration velocity $M$ of the river for density F3 and for different dependencies of the erodibility on the biomass density. The migration velocity are here made non-dimensional with the ratio between the river mean wavelength and the river temporal scale. Thus the floodplain is eroded at different time scales that depend on the adopted erodibility equation. Finally, Perucca et al. (2007) have also shown that the meander shape depends on the vegetation density function combined with the value of the friction coefficient of the river bed (Thorne and Furbish, 1995) in order to give rise to differently tilted from usual meander shapes.

\section{Stochastic approach}

\section{Application to braided rivers}

The Maggia River floodplain. The Maggia valley is located in the south-eastern part of the Swiss Alps. The topography of the central part of the valley is characterized by steep slopes, which end on the almost 2-km wide alluvial floodplain of the Maggia River (e.g, see Fig. 5a). Here, single threads or braided reaches determine river morphology. The alluvial material in situ has a high permeability, which allows for infiltration and exfiltration processes to occur (see Ruf et al., 2008). The corresponding hydrological basin has a surface of $568 \mathrm{~km}^{2}$ and an elevation ranging between 200 and $3300 \mathrm{~m}$ a.s.l. In the upper part of the valley, the two glaciers of Basodino and Cavagnoli, together with the mountainous snowfall precipitation, contribute to the glacionival hydrological regime of the basin. After impoundment by dams in 1953, the hydrological regime of the valley (Fig. 5b) has changed considerably (Pfamatter and Zanetta, 2003) to a generally constant hydrograph (environmental flow requirements are met at a discharge of $\sim 1.5 \mathrm{~m}^{3} \mathrm{~s}^{-1}$ ) and sporadic flood peaks (Fig. 5c) with almost uncorrelated flow magnitude and interarrival time (see, Molnar et al., 2008; Perona et al., 2009).

The river bed is made of alluvial gravel with a mean diameter of $120 \mathrm{~mm}$ (Sturzenegger, 2005). Despite the continuous morphological evolution of the Maggia floodplains, three nearly stable longitudinal bands are evident along the valley. The first band is the river bed, mostly characterized by water and sediments, on which only pioneer plants such Sagebrush (Artemisia campestris, Asteraceae) and Rosemary Willow (Salix elaeagnos, Salicaceae) can flourish. Such plants generally develop rapidly between floods and can regenerate each year being able to withstand lack of nutrients, and extremes of humidity, anoxia and temperature. The second band is made up of alluvial terraces surrounding the river bed, which are almost occupied by Salix elaeagnos, Alnus incana and Populus nigra. The third band of the valley includes terraces that are the furthest and most elevated from the watercourse, and therefore very rarely flooded. Here the soil is more mature and discrete layers of humus are also present. Such conditions are ideal for the development of latesere species, e.g. Ash (Fraxinux excelsior), Oak (Quercus robur), Small-leaved Lime (Tilia cordata) and Scots Pine (Pinus sylvestris). 
A lumped model based on aerial photographs observations. From a historical record of 10 (eight in the postdam period) aerial photographs (see Fig. 5a) and one manual survey (2006), we observed floodplain changes to be mainly correlated to i) erosional and sedimentation processes due to flood disturbance, and ii) the tendency of riparian vegetation to recolonize the exposed material (Molnar et al. 2008; Perona et al., 2009). In particular, for the postdam period, the amount of newly exposed area of sediment and water correlates well to flood occurrence and to the area inundated by the mean daily streamflow maxima above a threshold $q^{*}$ (Perona et al., 2009). Moreover, the timing and magnitude of floods show clear footprints of a Poisson process (i.e., exponentially distributed interarrival time) marked by an exponential distribution of magnitudes (Perona et al., 2009). From georeferenced aerial photographs, we were able to distinguish and classify vegetation serial stages (Fig. 5d,e) and related covered area as low, middle, and high (here referred to as grass $A_{G}$, shrubs $A_{S}$ and forest $A_{F}$ for the sake of simplicity), and build persistence maps for each vegetation class. However, from this information our understanding of how transitions between one stage of vegetation to another occurs cannot go further than ascribing it to a simple successional rule. That is, from time to time middle vegetation stages originate from low stages and high vegetation stages originate from middle stages, and all stages can be removed by floods sequentially. Accordingly, these elements offer the basis for a minimalist modelling approach (Perona et al., 2009), i.e. accounting only for those dynamics whose effects are evident at the reach scale (e.g., sedimentation and erosion, colonization by vegetation). The main structure of the model is summarized hereafter, whilst the reader is referred to Perona et al. $(2008,2009)$ for mathematical details.

We describe how the area of sediment and water $A_{S W}$, and that covered by vegetation $A_{v}=A_{G}+A_{S}+$ $A_{F}$ evolve within the reference domain $A_{d}=A_{S W}+A_{v}$ (e.g., the braided reach around Someo, Fig. 5b). This dynamic results from the interaction between stochastic flood disturbances and the subsequent deterministic colonization by riparian vegetation. Such a process is obviously lumped at the floodplain scale and it is described by the model equation

$\frac{d A_{S W}}{d t}=\Theta\left(\Delta A_{S W}\right) \cdot \Delta A_{S W}-C_{G}$.

$\Delta A_{S W}=A(t)-A_{S W}$ is the amount of new exposed sediment due to a stochastic disturbance of ampli- tude $A$ and conditional to the current exposed area $A_{S W}$ by means of the Heaviside function $\Theta(\cdot)$ (whose numerical value is 1 if $\Delta A_{S W}>1$, and zero otherwise). Since we deal with open systems, we assume that vegetation may originate from numerous agents (transport by wind, woody debris, leaves, etc.) and start colonizing with a rate proportional to the available area of exposed sediment. Hence, the term $C_{G}=k_{G} \cdot A_{S W}$, describes the area-dependent colonization rate of low stage vegetation, which depends on the colonization rate parameter of that class $k_{G}$. The area available for colonization decreases exponentially in time, thus accounting in a simplified way for the environment's carrying capacity. Equation (2), solely depending on the exposed area of sediment and water, can be solved analytically (Perona et al., 2009). Moreover, it can be coupled to a second set of equations to explicitly describe the successional stages among vegetation classes that are observed in the aerial photographs (Perona et al., 2008),

$$
\begin{aligned}
\frac{d A_{G}}{d t}= & C_{G}-C_{S}-\Theta\left(\Delta A_{S W}\right) \cdot\left[\Theta\left(A_{G}-\Delta A_{S W}\right)\right. \\
& \left.\cdot \Delta A_{S W}+\Theta\left(\Delta A_{S W}-A_{G}\right) \cdot A_{G}\right] \\
\frac{d A_{S}}{d t}= & C_{S}-C_{F}-\Theta\left(\Delta A_{S W}\right) \cdot \Theta\left(\Delta A_{S W}-A_{G}\right) \\
& \cdot\left[\Theta\left(A_{G, S}-\Delta A_{S W}\right) \cdot\left(\Delta A_{S W}-A_{G}\right)\right. \\
& \left.+\Theta\left(\Delta A_{S W}-A_{G, S}\right) \cdot A_{S}\right] \\
\frac{d A_{F}}{d t}= & C_{F}-\Theta\left(\Delta A_{S W}\right) \cdot \Theta\left(\Delta A_{S W}-A_{G, S}\right) \\
& \cdot\left[\Theta\left(A_{G, S, F}-\Delta A_{S W}\right) \cdot\left(\Delta A_{S W}-A_{G, S}\right)\right. \\
& \left.+\Theta\left(\Delta A_{S W}-A_{G, S, F}\right) \cdot A_{F}\right]
\end{aligned}
$$

Eq. (2) together with Eqs. (3-5) form a linear nonsmooth Master-Slave dynamical system forced by stochastic disturbances. This name ascribes to the particular type of one-directional coupling, which sees Eq. (2) substantially independent from Eqs. (3-5), but not viceversa. The term $C_{S}=k_{S} \cdot A_{G}$ represents the rate at which middle stage vegetation originates from the amount present at the low stage. Similarly, $C_{F}=k_{F} \cdot A_{S}$ describes the rate at which the highest stage vegetation evolves from the amount of area covered by middle stage vegetation. The parameter $k_{G}, k_{S}$, and $k_{F}$ can either be calibrated following a numerical procedure based on error minimization, or be estimated from observations from a time lapse period within which no disturbances have occurred.

In its simplicity, this modelling formulation mirrors the experimental observation and the role of top- 
ography on promoting vegetation to advanced stages. Accordingly, flood disturbances expose new material by removing vegetation stages (e.g., mortality due to floods) sequentially. The model (2-5) shows some interesting dynamical properties, here illustrated by a brief discussion about its equilibrium points. By definition, a system equilibrium point is reached when $d A_{i} / d t=0$, whereas the type of equilibrium (e.g., stable or unstable) depends on system's behaviour around that point (see Kaplan and Glass (1995) for an overview). If disturbances are active (i.e., in the model when $\left.q>q^{*}\right)$, the system always shows stationarity (in a statistical sense) because of the domain boundaries (Perona et al., 2008). If disturbances become ineffective (i.e., in the model when $q<$ $\left.q^{*}\right)$, the model reaches the deterministic equilibrium point located at $A_{F}=A_{d}$ and $A_{S W}=A_{G}=A_{S}=0$. This means, in the absence of floods acting as "natural cleaners", the whole domain $A_{d}$ is eventually colonized by high stage vegetation (Figure 6). In the linear picture offered by the model, $95 \%$ of the domain would be colonized in about 60 years. This equilibrium point is also absolutely stable. That is, if perturbed by a sporadic flood, the system always tends to return to its equilibrium point as soon as disturbances become ineffective (i.e., $q<q^{*}$ ).

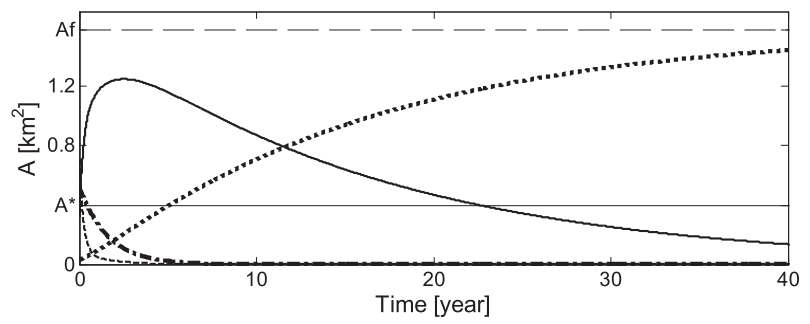

Figure 6. (a) Example of how the stable equilibrium point is reached after the complete removal of disturbances. Parameters: $q^{*}=76 \mathrm{~m}^{3} \mathrm{~s}^{-1} ; k_{G}=0.00171 / d ; k_{S}=7.2 k_{G} ; k_{F}=0.1 k_{G}$. Bold dashdotted line is water and sediment, dashed curve is grass, continuous line is shrubs, and dotted-bold line is forest. Initial condition: $A_{S W}(0)=0.33 A_{d} ; A_{G}(0)=0.45 A_{d} ; A_{s}(0)=0.2 A_{d}$ and $A_{F}(0)=$ $0.02 A_{d}$. The time axis is here shown only for the season where the process is active that is, the real time scale is obtained by multiplying by 1.49 .

From lumped to cross-section river-vegetation dynamics via dichotomic noise modelling. An exemplary application of another minimalist approach to obtain an explicit representation of the overall vegetation biomass of the phreatophyte riparian species distribution across a river section is now made by using the stochastic model of Camporeale and Ridolfi (2006). Such model allows in fact to obtain realistic results, in agreement with field observations (Johnson et al., 1995). The main structure of the model is briefly described here. Camporeale and Ridolfi (2006) con- sidered a quasi-trapezoidal river cross-section and assumed a probability distribution, $p(h)$, of the river water stages. The morphology of the transect is assumed steady and independent from vegetation distribution. Moreover, no inter-specific cooperation and competition processes are explicitly modelled. Under these hypotheses, the local stochastic dynamics of the dimensionless density biomass, $v$, of singlespecies riparian vegetation can be modelled at a generic plot of the riparian transect according to the following dichotomic process (Camporeale and $\mathrm{Ri}$ dolfi, 2006)

$\frac{d v}{d t}=\left\{\begin{array}{cc}-\alpha v^{n} & h \eta \\ v^{m}(\beta-v)^{p} & h<\eta\end{array}\right.$

where the exponents $m, n$ and $p$ depend on vegetation characteristics, while $h$ and $\eta$ are the water level of the river and the topographic elevation of the plot, respectively (Camporeale and Ridolfi, 2006). Equations $(6 a-b)$ switch, according to whether the site is inundated or not. The statistical characteristics of the dichotomic switching are dictated by the river stages and are described by the probability distribution, $p(h)$, and the correlation timescale, $\tau$ of the water level series, which represents a 'memory' of the hydrological forcing. Hence, despite neglecting the interactions of vegetation with geomorphological processes, this model accounts for the essential role that both the surface and the groundwater table fluctuations have on vegetation processes.

Equation $(6 a)$ models the decay of the vegetation biomass caused by flooding and assumes that the eventual beneficial influences are overcome by the detrimental processes (i.e., anoxia, burial, uprooting, etc.). In particular, the coefficient $\alpha$ depends on the plant species and on $h$, thus allowing to account for both the mechanical and the anoxic conditions exerted on vegetation by water level increase (Friedman and Auble, 1999). Equation (6b) is a generalization of the commonly used Verhulst-logistic function, which simulates the growth of a phreatophyte species that taps the groundwater (Botkin et al., 1972). $\beta$ is the carrying capacity (i.e., the maximum sustainable biomass), which depends on the depth of the aquifer water table through the quadratic optimum function, as suggested by Phipps (1979). Equations $(6 a-b)$ can be rewritten as a single stochastic differential equation, driven by multiplicative dichotomic noise (Kitahara et al., 1980), whose solution in steady state conditions is the probability distribution of the vegetation density, $p(v)$. For sake of simplicity we assume $n=m=p=l$ and in this case the distribution reads 
Table 1. Mean of the observed and simulated coverage of water and sediment, low, middle and high vegetation stages in the period $1962-$ 2006 and for the year 2004. The coverage indicated with "other" corresponds to areas affected by human activity, which are therefore not included in the model.

\begin{tabular}{|c|c|c|c|c|c|c|}
\hline \multirow[b]{2}{*}{ stage } & \multicolumn{3}{|c|}{ mean value $1962-2006$} & \multicolumn{3}{|c|}{2004} \\
\hline & $\begin{array}{c}\text { observed } \\
{\left[\mathbf{k m}^{2}\right]}\end{array}$ & $\begin{array}{c}\text { simulated } \\
{\left[\mathbf{k m}^{2}\right]}\end{array}$ & $\begin{array}{c}\text { error } \\
{[\%]}\end{array}$ & $\begin{array}{c}\text { observed } \\
{\left[\mathrm{km}^{2}\right]}\end{array}$ & $\begin{array}{c}\text { simulated } \\
{\left[\mathrm{km}^{2}\right]}\end{array}$ & $\begin{array}{c}\text { error } \\
{[\%]}\end{array}$ \\
\hline ws & 493470 & 520390 & $5.46 \%$ & 450510 & 430800 & $-4.38 \%$ \\
\hline low & 102000 & 99280 & $-2.67 \%$ & 62740 & 96430 & $53.70 \%$ \\
\hline middle & 363970 & 320770 & $-11.87 \%$ & 276170 & 341410 & $23.62 \%$ \\
\hline high & 597380 & 617270 & $3.33 \%$ & 773330 & 689060 & $-10.90 \%$ \\
\hline other & 19480 & 18590 & - & 13550 & 18600 & 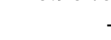 \\
\hline
\end{tabular}

$p(v)=\frac{N}{\alpha} v^{\frac{\beta(1-\alpha \tau)-(\alpha+\beta) P_{t}}{\alpha \beta \tau}}(\beta-v)^{\frac{P_{t}}{\beta \tau} t}(\alpha+\beta-v)$,

where $v \in[0, \beta], P_{I}$ is the inundation probability, and $N$ is the normalization constant. The above solution is valid for $P_{\mathrm{I}}<\beta /(\alpha+\beta)$, otherwise $p(v)=\delta(v)$, where $\delta(\cdot)$ is the Dirac delta function.

The analytical relation (7) allows to study how the transversal distribution of the riparian vegetation depends on hydrological, morphological, and biological parameters that are represented in the model. As Camporeale and Ridolfi (2006, 2007) have shown, for a Standard Gamma distribution of the water stage levels the average vegetation biomass varies along the $x$-direction, from zero close to the river, up to a maximum value and, then, it slowly decreases asymptotically approaching the average value of the carrying capacity, $\beta(x)$, at a high $x$. This behavior of the mean along the riparian transect is coherent with the F3 distribution previously assumed (see Fig. 2) and is well explained by inundations that frequently destroy vegetation close to the river, and by the monotonic decrease in the carrying capacity along the transect due to a progressive increment in the water table depth. As far as the coefficient of variation, $C_{b}$ is concerned, this affects both the location of the vegetated zone and the peak value. That is, the riparian vegetation shifts away from the river and the overall mean amount of riparian biomass (i.e., $\left.\int_{-1}^{\infty} \mu_{v} d x\right)$ decreases when the discharge variability increases, because of the increasing occurrence of inundation events. A similar role is played by the biological parameter $\alpha$, with a decrease in the tolerance to water stress caused by inundation as $\alpha$ increases. This causes an outward shift of the vegetated zone and a consequent increase of the nonvegetated zone close to the river (Camporeale and Ridolfi, 2007).

\section{Results and discussion}

From modelling to sustainable water management

As shown in Perona et al. (2008, 2009), the lumped model was calibrated on the 1962-2001 observations and by using the historical record of uncorrelated flood disturbances in the postdam period. For the sake of a comparison, model parameters were also directly estimated from data (see Perona et al., 2009), operation that would be preferable to numerical calibration provided that sufficient data are available. Due to the limited amount of aerial photographs, model validation was only possible by using the last two available observations (2004 and 2006). Although these results are not shown here (Perona et al., 2008, 2009), we briefly recall that based on the successional dynamics on which it is built, the model shows that sediment (i.e., $A_{S W}$ ) is frequently exposed by floods, the size of which determine the disappearance of the area covered by low vegetation (i.e., $A_{G}$ ) first, then the middle stage (i.e., $A_{S}$ ), and finally the high stage (i.e., $\left.A_{F}\right)$. However, this class of vegetation is less affected by disturbances and clearly shows the presence of a transitory phase; e.g. a nearly monotonic growth in the postdam period. In summary, the model catches the trends and the different fluctuations affecting all classes showing that the observed mean for all classes reasonably compares against the computed ones (Table 1).

The good agreement between observations and modelled data seems to support the idea that the daily mean magnitude of the disturbances explains satisfactorily well the process exposing sediment in the floodplain. In our case, such results hold for the specific postdam period and for the lumped reach scale that is analyzed. In general, in order to assure transferability to nonimpounded sites or to describe the predam period in the Maggia valley, one should account for the timing, duration and correlation among the disturbances. This motivates our interest in applying the model with dichotomic noise to a crosssection of the River Maggia for both the pre and the postdam periods. 
We first identified a nearly stable cross-section within the domain used for the lumped model (Fig. 7). Then, from the numerical 2D flow simulations of Ruf et al. (2008), we obtained the flow rating curve $h=$ $h(q)$ under steady conditions by averaging the water surface level of the wet cells in the cross section. This smoothing is useful to reduce the cell-to-cell water level variability due to the limited accuracy of the adopted Digital Elevation Model and to computational errors. We then used $h=h(q)$ to obtain the steady state water surface dynamics from the historical record of daily mean streamflows. From the analysis of the historical daily mean river discharge, two different probability distribution functions for the water level across the river section (with mean $\mu_{h}$ and variance $\sigma_{h}$ ), and two different values of the related autocorrelation times $\tau$ are calculated for both the predam and the postdam periods. We obtained $\mu_{h}=$ $0.92 \mathrm{~m}, \sigma_{h}=0.05 \mathrm{~m}^{2}$ and $\tau=32$ days for the predam conditions, and $\mu_{h}=0.6 \mathrm{~m}, \sigma_{h}=0.03 \mathrm{~m}^{2}$ and $\tau=11$ days for the postdam conditions. In order to set the model vegetation parameters, we consider the existence of three different vegetation types, i.e. grass, shrubs and forest. With the help of the aerial photographs and the manual survey made in 2006, we summarize the characteristic time for growth and decay for such vegetation types into three parameter sets. However, aerial photographs allowed us to obtain information only about the vegetation type and not about the biomass density of each class of vegetation. Thus, we limited our analysis to verify if the model is able to predict the occurrence or the nonoccurrence of a certain type of vegetation for both the pre- and the postdam periods. We therefore partitioned the river cross-section into 60 points and for each of them we used the dichotomic model to predict the existence of the three types of vegetation described above. When the model predicted an expected value of pdf of the vegetation density biomass different from zero (i.e., $\mu_{v}>0$ ) we set an occurrence of the vegetation showing the higher biomass mean in that point. The same point would be set to a lack of that type of vegetation, otherwise. On this basis we obtained the results summarized in figure 8. It can be observed that the change in the hydrological regime forced by the dam-regulation has led to a substantial change in vegetation composition of the transect in the postdam period. That is, decreasing in water stress condition (i.e., inundation of a given point) led to the proliferation of the forest vegetation type. Such a trend is predicted by the dichotomic model and seems to be well in agreement with the data obtained from the historical aerial photographs. Some exceptions are however present, and are related to the shortcomings of the model,

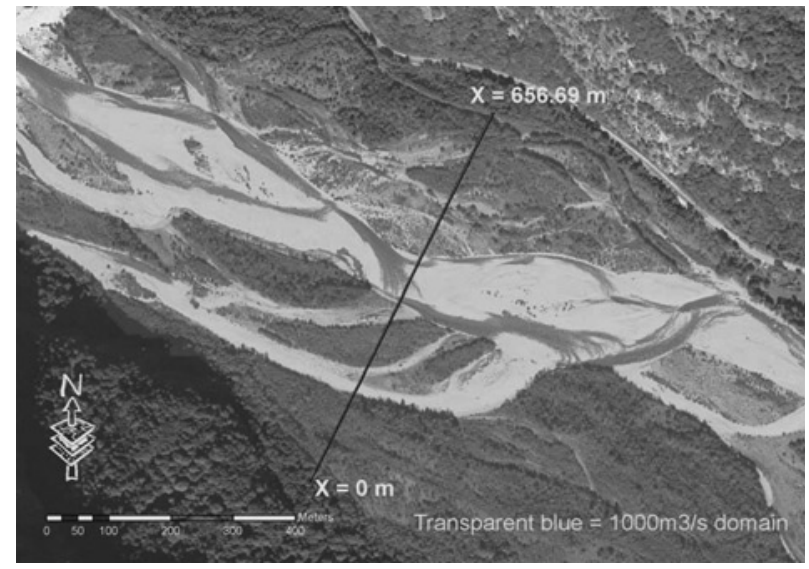

Figure 7. Location of the cross section used for the dichotomic model within the domain of the lumped model.

which is in fact strongly elevation-dependent. This causes the model to be unable to distinguish different plots with the same elevation but located at different distances from an active channel, since the 2D fluid dynamics of the flow are not accounted for here.

We offer now a discussion based on the use of both stochastic models to promote a sustainable management of the water resources in the valley. Accordingly, we investigate the effect of artificial flood disturbances as controlled releases by dams on floodplain processes. We investigate a general "what if" scenario by modifying the historical recorded streamflow by adding each year an artificial disturbance of magnitude equal to the actual historical daily mean (i.e. $\mu=$ $164 \mathrm{~m}^{3} \mathrm{~s}^{-1}$ ) and duration proportional to similar events that had occurred in the past. One exemplary year of the modified historical hydrograph is shown in Figure 9. Some interesting questions arise about what the floodplain would look like today if such a sequence of additional disturbances had perturbed the valley since the hydropower began to operate. In this sense, modelling is clearly the only way one can explore such a hypothesis. To this purpose, we again ran the two models to evaluate their outcomes. The lumped model clearly shows that a bigger exposed area of sediment and water would characterize the valley today (e.g., $+10 \%$ ), with a sensible decreasing of all the classes of vegetation (see Fig. 10). Obviously, such results reflect the simple linear structure of the model itself, but they are, however, interesting because they go in the expected direction. That is, they suggest a general shift backward of the pdfs of vegetation classes and a shift forward of the one related to the sediment and water class. Moreover, the pdfs also change their amplitude, thus showing that also the second order moment (i.e., the variance of the process) would change in general. The distribution of 


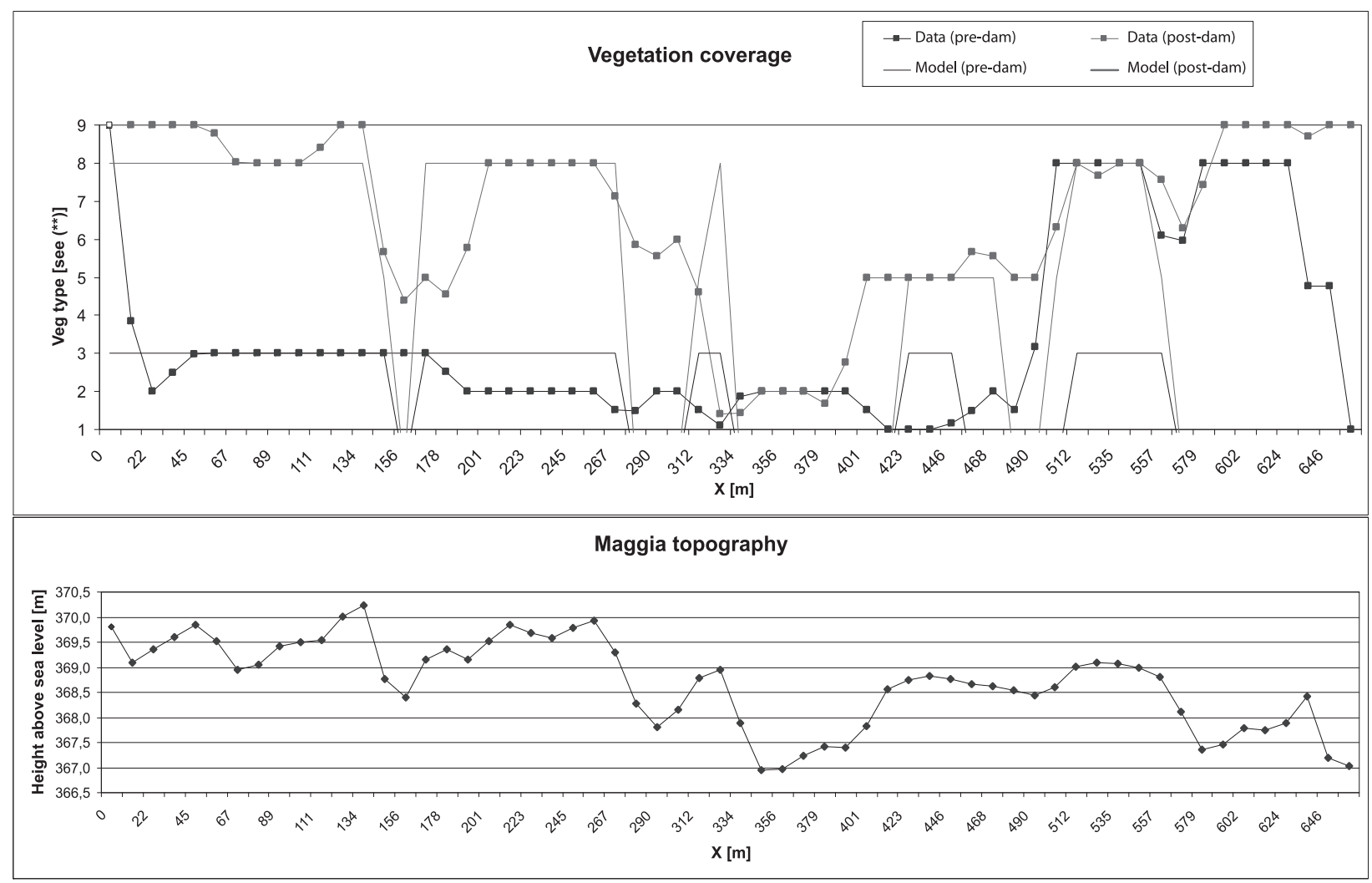

Figure 8. (a) Comparison between the real data and the output of the dichotomic model for the occurrence of grass and forest in the transect of the Maggia river. The different levels in the coordinate axis refers to different type of vegetation (1-2: sediment; 3 : grass; 4-7: shrubs; 8-9: forests. (b) Topography of the cross section).

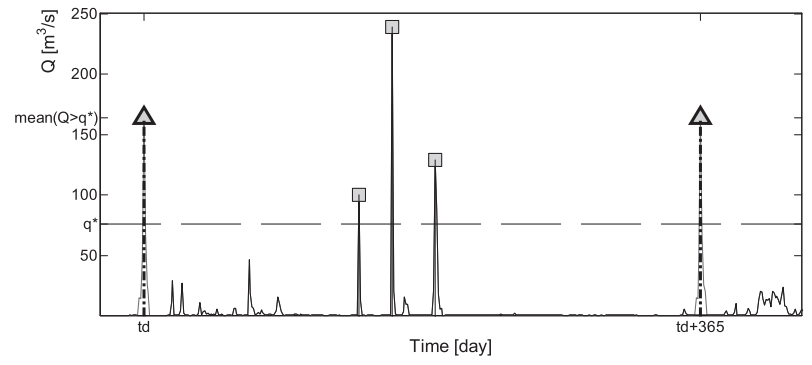

Figure 9. Historical daily mean hydrograph (continuous curve) and related peaks (square) for the postdam period. Artificial disturbances (dashed curve) and related peaks (triangle). $q^{*}=76$ $m^{3} \mathrm{~s}^{-1}$; mean $\mu=163.97 \mathrm{~m}^{3} \mathrm{~s}^{-1}$.

the water levels $p(h)$ would not be altered in a dramatic way by the introduction of the disturbances. Such a quantity plays a strong role in the dichotomic model, which predicts vegetation mortality as a result of anoxia due to prolonged inundation rather than erosional processes due to floods. Thus, for such a model, the introduction of the artificial disturbances will not modify the distribution of the vegetation classes with respect to those shown in figure 8. However, the decrease in the autocorrelation time of the water stage (e.g., from $\tau=11$ to $\tau=5$ days) due to the artificial disturbances have the effect of reducing the variance of the solution of the model, that is the pdf of the biomass density. This effect is extensively described in Camporeale and Ridolfi (2006), where it was observed that the solution of the pdf resulted in many cases in a Dirac delta function centered in $v=$ $\mu_{v}$.

The release of artificial disturbances has a cost as far as the use of water for hydropower is concerned, and indirectly this cost will reflect as an additional burden on the local population. At this point, accurate market research should obviously be conducted in order to assess the feasibility of the solution discussed above, also from an economic viewpoint and on the base of the willingness to pay of the involved inhabitants of the valley. Beyond all these factors, the impact of climatic change on the future availability of water should also be considered in order to guarantee that enough water is on average still available to recharge the dams after the releases. Hence, it is precisely at this point that the use of models will come into play an important role, for instance by helping the negotiation phase between Cantonal authorities and stakeholders (e.g., hydropower in this case) who are competing for water use. 


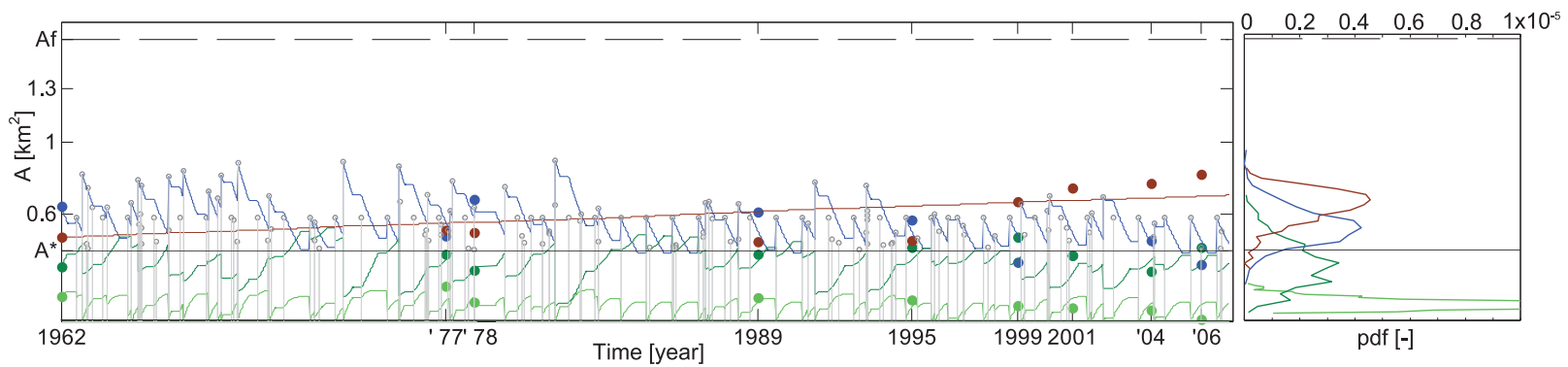

Figure 10. Predicted floodplain evolution when running the model with artificial disturbances and related pdfs (right panel). The dots represent the observations and are used as a comparison. Water and sediment (blue), grass (light green), shrubs (green), forest (red). Mean exposed areas for all classes are: $\bar{A}_{S W}=527752 \mathrm{~m}^{2} ; \bar{A}_{G}=94072 \mathrm{~m}^{2} ; \bar{A}_{S}=317029 \mathrm{~m}^{2} ; \bar{A}_{F}=637446 \mathrm{~m}^{2}$. Model parameters are: streamflow threshold $q^{*}=76 \mathrm{~m}^{3} \mathrm{~s}^{-1}$; disturbances mean interrarival time and magnitude $\tau=105$ days; $\beta=163.97 \mathrm{~m}^{3} \mathrm{~s}^{-1}$; Colonization parameters $k_{G}=$ $0.00171 / \mathrm{d} ; k_{S}=3 k_{G} ; k_{F}=0.04 k_{G}$

\section{Conclusions}

Modelling approaches are essential to understand morphodynamic changes in relation to river and riparian vegetation interactions whenever the size and complexity of most floodplain processes makes experimental approaches difficult over the medium to long term. In this sense, modelling acts as a virtual laboratory tool which helps scientists from different disciplines to establish a common link between the ecological, geomorphological, hydrological and hydraulics viewpoints. Efforts in this direction at the medium to long term are particularly useful for scientific projects exploring the basis for river restoration dynamics, the construction of ecologically compatible flood protection measures, the release of environmental flow regimes in water impounded systems, etc., with all the subsequent benefits and burdens that these measures imply with respect to ecosystem functioning. The minimalist models discussed in this paper obviously simplify the true complexity of river and vegetation interactions. It should be borne in mind, however, that their use aims at accounting for environmental noise affecting the system's dynamics, the effect of which is to blur small scale processes. In this work we have shown the advantages of having understood the role of the few parameters involved in each model, and how to use such models in a perspective oriented toward the development of integrated measures that may help planning more sustainable uses of water resources in alpine environments.

\section{Acknowledgments}

This work originated from the workshop "Linkages and feedbacks in highly dynamic, alpine, fluvial systems" held in Cornino (I) in the Summer 2008 and granted by the European Science Fundation
(ESF), which is therefore acknowledged. Authors wish also to thank BAFU (Grant No. R-03-02) for financial support, Franziska Stössel for carrying out the manual survey of the floodplain vegetation in 2006 and Stefano Tealdi for having carried out the computation with the dichotomic model.

\section{References}

Anderson, M. G., D. Walling and P. D. Bates, 1996. Floodplain Processes. John Wiley and Sons., Chichester.

Baptist, M., W. Penning, H. Duel, A. Smits, G. Geerling, G. Van Der Lee and A. J. S. L., 2004. Assessment of the effects of cyclic floodplain rejuvenation on flood levels and biodiversity along the Rhine River. River Res. Applic. 20: $285-297$.

Baptist, M., L. van den Bosch, J. Dijkstra and S. Kapinga, 2005. Modelling the effects of vegetation on flow and morphology in rivers. Large Rivers 15(1-4): 339 - 357.

Bertoldi, W., S. Miori, M. Salvaro, L. Zanoni and M. Tubino, 2006. Morphological description of river bifurcations in gravel-bed braided networks. River Flow 2006 - Proceedings and Monographs in Engineering, Water and Earth Sciences 1-2: $1311-1318$.

Bertoldi, W. and M. Tubino, 2007. River bifurcations: Experimental observations on equilibrium configurations. Water Resour. Res. 43: W10437.

Bolla Pittaluga, M., M. Repetto and M. Tubino, 2003. Channel bifurcation in braided rivers: Equilibrium configurations and stability. Water Resour. Res. 39(3): 1046.

Botkin, D. B., J. F. Janak and J. R. Wallis, 1972. Some ecological consequences of a computer model of forest growth. J. Ecology 60: $849-872$.

Bradley, C. E. and D. G. Smith, 1986. Plains cottonwood recruitment and survival on a prairie meandering river floodplain, Milk River, Southern Alberta and Northern Montana. Can. J. Bot. 64: $1433-1442$.

Brookes, C. J., J. M. Hooke and J. Mant, 2000. Modelling vegetation interactions with channel flow in river valley of the Mediterranean region. Catena 40: $93-118$.

Brooks, A. P. and Brierley, G. J., 2002 Mediated Equilibrium: The Influence of Riparian Vegetation and Wood on the Long-Term Evolution and Behaviour of a Near-Pristine River. Earth Surf. Process. Landforms 27: $343-367$.

Camporeale, C., P. Perona, A. Porporato and L. Ridolfi, 2007. Hierarchy of models for meandering rivers and related morphodynamic processes. Rev. Geophys. 45 RG1001.

Camporeale, C. and L. Ridolfi, 2006. Riparian vegetation distri- 
bution induced by river flow variability: a stochastic approach Water Resour. Res. 42: W010415. 10.1029/2006WR004933.

Camporeale, C. and L. Ridolfi, 2007. Noise-induced phenomena in riparian vegetation dynamics. Geophys. Res. Letts. 34(18).

Carr, C. J., 1998 Patterns of Vegetation Along the Omo River in Southwest Ethiopia. Plant Ecology 135: 135 - 163.

Coulthard, T., 2005. Effects of vegetation on braided stream pattern and dynamics. Water Resour. Res. 41(4).

Coulthard, T. J., D. M. Hicks and M. J. Van De Wiel, 2007. Cellular modelling of river catchments and reaches: Advantages, limitations and prospects. Geomorphology 90(3-4): 192 - 207.

D’Odorico, P., F. Laio, and L. Ridolfi, 2005. Noise-induced stability in dryland plant ecosystems. Proc. Nat. Acad. Sci. United States of America 102(31): 10819 - 10822.

D'Odorico, P., F. Laio and L. Ridolfi, 2006. A probabilistic analysis of fire-induced tree-grass coexistence in savannas. American Naturalist 167(3): E79 - E87.

Fonda, R. W., 1974. Forest succession in relation to river terrace development in Olympic National Park, Washington. Ecology 55: $927-942$.

Friedman, J. M. and G. T. Auble, 1999. Mortality of riparian box elder from sediment mobilization and extended inundation. Regul. Rivers Res. Mgmt. 15: 463 - 476.

Glenz, C., 2005. Process-based, spatially-explicit modelling of riparian forest dynamics in central Europe - tool for decision making in river restoration. $\mathrm{PhD}$ thesis, EPFL, Lausanne.

Gran, K. and C. Paola, 2001. Riparian vegetation controls on braided stream dynamics. Water Resour. Res. 37(12): 3275 3283.

Gurnell, A. and G. Petts, 2006. Trees as riparian engineers: The Tagliamento River, Italy. Eart Surf. Proc. Landforms 31(12): $1558-1574$.

Gurnell, A., G. E. Petts, D. M. Hannah, B. P. G. Smith, P. J. Edwards, J. Kollmann, J. V. Ward and K. Tockner, 2001. Riparian vegetation and island formation along the gravel-bed fiume Tagliamento, Italy. Earth Surf. Process. Landforms 26: $31-62$.

Hooke, J., C. Brookes and J. Mant, 2005. A simulation model of the morphological, vegetation and sediment changes in ephemeral streams. Geophys. Res. Lett. 30: LO3402. doi:10.1029/ 2004GL021966.

Hutt, M. and U. Luttge, 2002. Nonlinear dynamics as a tool for modelling in plant physiology. Plant Biology 4(3): 281 - 297.

Imran, J., G. Parker and C. Pirmez, 1999. A nonlinear model of flow in meadering submarine and subaerial channels. J. Fluid Mech. 400: 295 - 331.

Jang, C. L. and Y. Shimizu, 2007. Vegetation effects on the morphological behavior of alluvial channels. J. Hydr. Res. 45(6): $763-772$.

Johnson, W., M. Dixon, S. Simons and K. Larson, 1995. Mapping the response of riparian vegetation to possible flow reductions in the Snake River, Idaho. Geomorphology 13: 159 - 173.

Kaplan, D. T. and L. Glass, 1995. Understanding nonlinear dynamics Springer, NewYork

Kitahara, K., W. Horsthemke, R. Lefever and Y. Inaba, 1980. Phase diagrams of noise induced transitions. Prog. Theor. Phys. 64(4): $1233-1247$.

Klausmeier, C., 1999. Regular and irregular patterns in semiarid vegetation. Science 284(5421): 1826 - 1828 .

Laio, F., P. D'Odorico and L. Ridolfi, 2006. An analytical model to relate the vertical root distribution to climate and soil properties. Geophys. Res. Letts. 33(18).

Larsen, E., E. Girvetz and A. Fremier, 2006. Assessing the effects of alternative setback channel constraint scenarios employing a river meander migration model. Environmental Management 37(6): $880-897$.

Lefever, R. and O. Lejeune, 1997. On the origin of tiger bush. Bull. Mathem. Biol. 59(2): 263 - 294.

Millar, R. G., 2000. Influence of bank vegetation on alluvial channel patterns. Water Resour. Res. 36(4): $1109-1118$.

Molnar, P., V. Favre, P. Perona, P. Burlando, C. Randin and W. Ruf,
2008. Floodplain forest dynamics in a hydrologically altered mountain river. Peckiana 5: $17-24$.

Mosselman, E., 1998. Morphological modelling of rivers with erodible banks. Hydrolog. Process. 12(8): $1357-1370$.

Muneepeerakul, R., A. Rinaldo and I. Rodriguez-Iturbe, 2007. Effects of river flow scaling properties on riparian width and vegetation biomass. Water Resour. Res. 43: W12406. 10.1029/ 2007WR006100.

Murray, A. B. and C. Paola, 2003. Modelling the effect of vegetation on channel pattern in bedload rivers. Earth Sur. Proc. Landforms 28(2): 131 - 143.

Nanson, G. C. and H.F. Beach, 1977. Forest succession and sedimentation on a meandering-river floodplain, North East British Columbia, Canada. J. Biogeogr. 4: 229 - 251.

Perona, P. and C. Camporeale, 2004. Influence of geometrical constraints on the evolution of meandering rivers. In Greco, M. and A. Carravetta, editors, River Flow 2004, International Conference on Fluvial Hydraulics. IAHR.

Perona, P., P. Molnar, M. Savina and P. Burlando, 2008. Stochastic sediment-vegetation dynamics in an alpine braided river. IAHS Publ. 325: 266 - 274.

Perona, P., P. Molnar, M. Savina and P. Burlando, 2009. An observations-based stochastic model for sediment and vegetation dynamics in the foodplain of an alpine braided river. Water Resour. Res. 45, W09418, doi: 10.1029/2008WR007550.

Perona, P., A. Porporato and L. Ridolfi, 2007. A stochastic process for the interannual snow storage and melting dynamics. Journal Geophys. Res. - Atmosphere 112(D8): D08107.

Perucca, E., C. Camporeale and L. Ridolfi, 2006. Influence of river meandering dynamics on the riparian vegetation pattern formation. J. Geophys. Res. 111: G01001. doi:10.1029/ 2005JG000073.

Perucca, E., C. Camporeale and L. Ridolfi, 2007. Significance of the riparian vegetation dynamics on meandering river morphodynamics. Water Resour. Res. 43: W03430. 10.1029/ 2006WR005234.

Pfamatter, S. and P. Zanetta, 2003. Hydrogologie de la plaine alluviale du valmaggia entre bignasco et giumaglio (Tessin). Master's thesis, Universitt Lausanne.

Phipps, R. L., 1979. Simulation of wetland forest dynamics. Ecol. Model. 7: $257-288$.

Pollen, N. and A. Simon, 2005. Estimating the mechanical effects of riparian vegetation on stream bank stability using a fiber bundle model. Water Resour. Res. 41: W07025. doi:10.1029/ 2004GL021966.

Poole, G., J. Stanford, C. Frissell and R. SW, 2002. Threedimensional mapping of geomorphic controls on flood-plain hydrology and connectivity from aerial photos. Geomorphology 48(4): 329 - 347.

Rietkerk, M. and J. Van de Koppel, 2008. Regular pattern formation in real ecosystems. Trends in Ecology \& Evol. 23(3): 169 - 175 .

Rodrigez-Iturbe, I. and A. Porporato, 2005. Ecohydrology of Water Controlled Ecosystems. Cambridge University Press, The Edinburgh Building Shaftesbury Road Cambridge CB2 2RU.

Rodriguez-Iturbe, I., A. Porporato, L. Ridolfi, V. Isham and D. R. Cox, 1999. Water balance at a point: The role of climate, soil and vegetation. Proc. R. Soc. Lond. A 455: 3789 - 3809.

Rodriguez-Iturbe, I. and A. Rinaldo, 1997. Fractal river basins: chance and self-organization. Cambridge University Press, New York.

Ruf, W., L. Foglia, P. Perona, P. Molnar, R. Faeh and P. Burlando, 2008. Modelling the interaction between groundwater and river flow in an active alpine floodplain ecosystem. Peckiana 5: $5-16$.

Seminara, G., 1998. Stability and morphodynamics. Meccanica 33: $59-99$.

Sturzenegger, M., 2005. Changes in river morphology and vegetation caused by stream-flow regulation: a case study in the Maggia Valley, Switzerland. Master's thesis, ETH/IHW.

Tal, M. and C. Paola, 2007. Dynamic single-thread channels 
maintained by the interaction of flow and vegetation. Geology 35(4): 347 - 350 .

Thorne, S. D. and D. J. Furbish, 1995. Influence of Coarse Bank Roughness on Flow Within a Sharply Curved River Bend Geology 12: 241 - 257.

Tubino, M. and G. Seminara, 1990. Free-forced interactions in developing meanders and suppression of free bars. J. Fluid Mech. 214: 131 - 159.

Van De Wiel, M. J. and S. E. Darby, 2004. Numerical modeling of bed topography and bank erosion along tree-lined meandering rivers. In Bennett, S. J. and A. Simon, editors, Riparian Vegetation and Fluvial Geomorphology, pages 267-282. American Geophysical Union, 2000 Florida Avenue, N. W. Washington, DC 20009.

Van Kampen, N. G., 1992. Stochastic processes in physics and chemistry. Elsevier, London.

Zolezzi, G. and G. Seminara, 2001. Downstream and upstream influence in river meandering. Part 1. General theory and application to overdeepening. J. Fluid Mech. 438: 183-211.

To access this journal online: http://www.birkhauser.ch/AS 